\title{
Ascending aortopathy with bicuspid aortic valve: More, but not enough, evidence for the hemodynamic theory
}

\author{
William M. DeCampli, MD, PhD
}

\footnotetext{
From the Heart Center, Arnold Palmer Hospital for Children, and Department of Clinical Sciences, University of Central Florida College of Medicine, Orlando, Fla.

Disclosures: Author has nothing to disclose with regard to commercial support.

Received for publication Oct 2, 2016; accepted for publication Oct 3, 2016

Address for reprints: William M. DeCampli, MD, PhD, The Heart Center, Arnold Palmer Hospital, 80 W Miller

St, Orlando, FL 32813 (E-mail: William.decampli@ucf.edu or William.decampli@orlandohealth.com).

J Thorac Cardiovasc Surg 2017;153:6-7

$0022-5223 / \$ 36.00$

Copyright (c) 2016 by The American Association for Thoracic Surgery

http://dx.doi.org/10.1016/j.jtcvs.2016.10.033
}

Bicuspid aortic valve (BAV) is the most common congenital cardiac defect and it is frequently associated with progressive dilation of the ascending aorta. Two theories exist to explain the association between BAV and ascending aortopathy - the genetic theory and the hemodynamic theory.

Even without stenosis or regurgitation, blood passing through a BAV is abnormally directed toward the greater curvature of the ascending aorta, often with slight flow acceleration. Studies using either 4-dimensional cardiac magnetic resonance imaging (CMR), or conventional magnetic resonance angiography (MRA) with computational fluid dynamics (CFD) have shown that flow asymmetry and helicity are increased in BAV, and that aortic wall shear stress (WSS) is greatly increased in the greater curvature of the aorta, compared with normal patients. ${ }^{2,3}$ Studies have demonstrated that these fluid dynamic stresses can promote local medial degeneration via matrix metalloproteinasedependent pathways. 4

Youssefi and colleagues ${ }^{6}$ add to the body of clinical evidence that aortic hemodynamic parameters are abnormal in BAV. They performed MRA with CFD studies on 5 groups of patients $(\mathrm{N}=45)$ with different valve pathologies. $\mathrm{Pa}$ tients with BAV with right-noncoronary leaflet fusion and aortic stenosis had the largest ascending aortas, greatest flow asymmetry, greatest mean WSS, and lowest oscillatory shear stress. Although the calculated values were generally in line with prior studies, the patient groups were not matched for age, body surface area, gender, or ventricular function; cardiac output was not adjusted for; and WSS was not indexed to aortic diameter. These omissions make comparison of the groups somewhat difficult to interpret. Inclusion of BAV groups without aortic stenosis and aortic regurgitation could have added significant insight to the analysis.

In a comparable work but using 4-dimensional CMR, Bissel and colleagues ${ }^{7}$ studied 142 subjects (95 with BAV and 47 normal controls) using groups with comparable distributions in age, peak velocity, regurgitant fraction, and left ventricular function. All hemodynamic variables in BAV abnormalities.

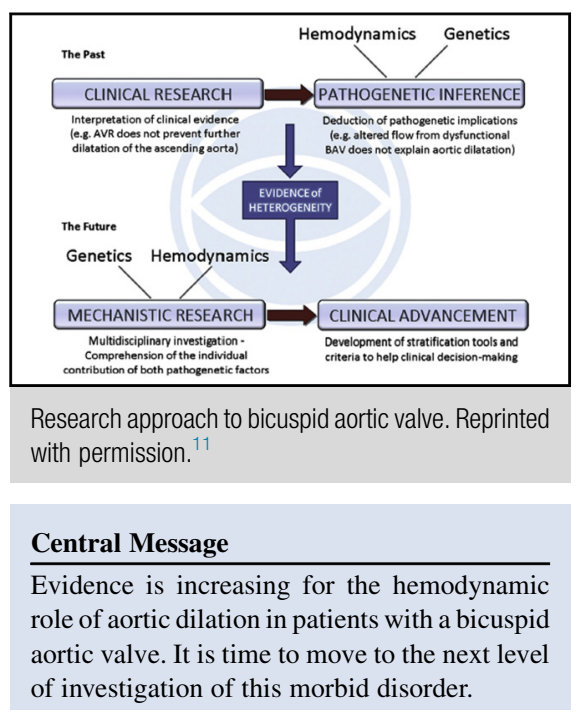

See Article page 8 .

with right-handed helical flow were abnormal compared with normal controls. Most variables were more abnormal in the right-noncoronary leaflet fusion group compared with the right-left fusion group. The presence of valve stenosis significantly accentuated most of the hemodynamic

The hemodynamic theory is supported by the fact that aortic valve replacement (AVR) seems to slow the progression of aortic dilation. In 93 patients undergoing AVR, Regeer and colleagues ${ }^{8}$ found that the preoperative rate of dilation was $0.42 \mathrm{~mm} /$ year (BAV) and $0.15 \mathrm{~mm} / \mathrm{year}$ (trileaflet) $(P=.02)$. Postoperatively, these values were $0.28 \mathrm{~mm} /$ year (regression coefficient [growth rate] with $95 \%$ confidence interval, $0.15-0.42 \mathrm{~mm} / \mathrm{year}$ ) and $0.35 \mathrm{~mm} /$ year (regression coefficient [growth rate] with $95 \%$ confidence interval, $0.24-0.46 \mathrm{~mm} /$ year), respectively $(P=.5)$. Kinoshita and colleagues ${ }^{9}$ studied 47 BAV patients undergoing AVR and found that the only variable associated with rapid postoperative dilation was greater-thanmoderate preoperative regurgitation.

We still have inadequate evidence to show which theory dominates, and the heterogeneity of this disorder suggests that both mechanistic pathways can coexist. This compels us to move to the next levels of investigation. CFD should incorporate formal fluid-structure interaction modeling. Four-dimensional CMR, augmented perhaps with intravascular ultrasound, must look with greater precision at aortic 


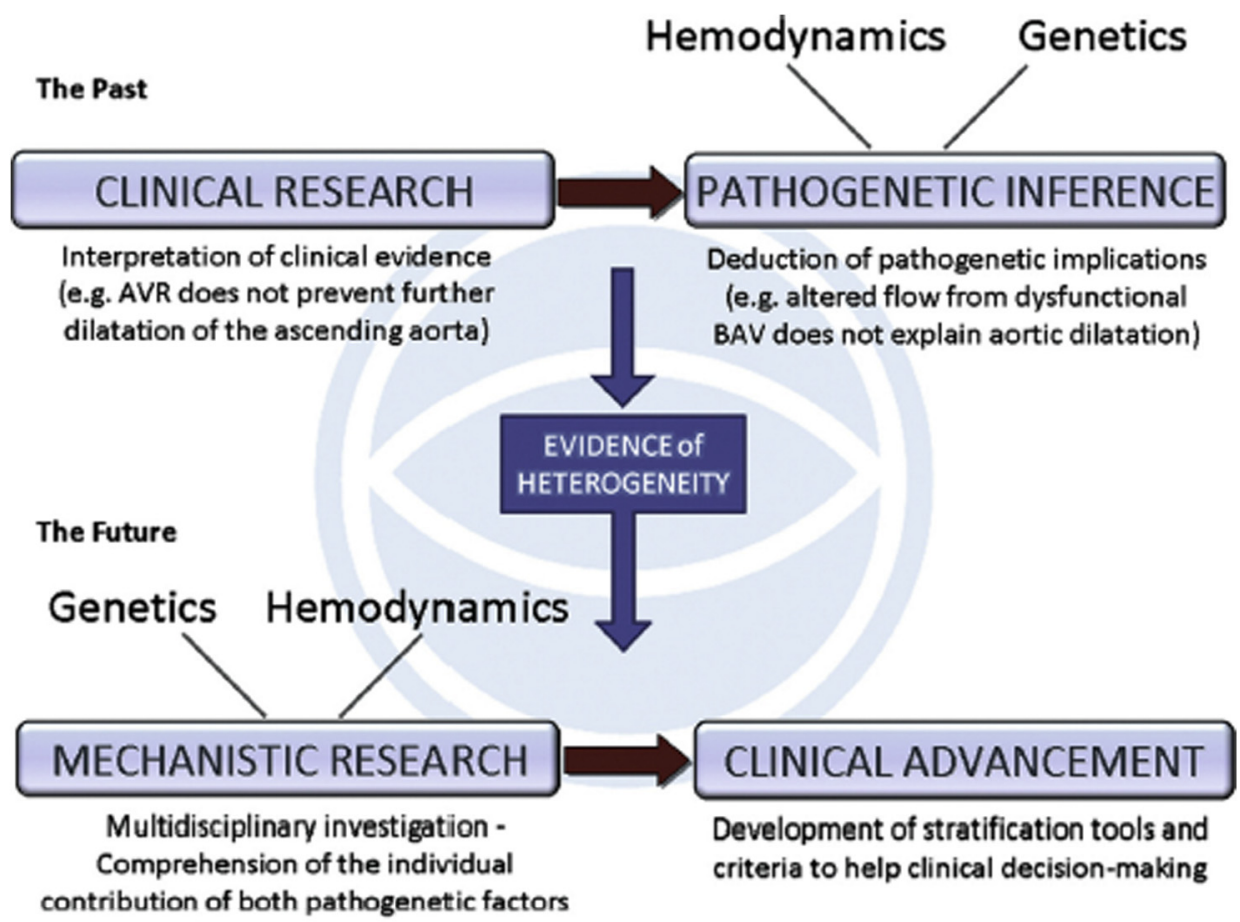

FIGURE 1. The research approach to BAVaortopathy: past and future. Up to a few years ago, research on BAVaortopathy interpreted clinical aspects (eg, rate of progression, relation with severity of valve dysfunction, risk of dissection) with the aim of drawing inferences on the pathogenesis, that is, alternatively supporting the hemodynamic or the genetic theory. Inconclusive results and increasing awareness of the phenotypic heterogeneity have led to an inversely oriented approach: the contribution of either pathogenetic factor is investigated to identify the respective potential prognostic value in the clinical setting. AVR, Aortic valve replacement; $B A V$, bicuspid aortic valve. Reprinted with permission. ${ }^{11}$

wall structure and mechanics. To distinguish between the competing theories, longitudinal studies using multivariable risk-hazard models are needed that account for standardized and state-of-the-art (eg, 4-dimensional CMR or MRA with CFD) hemodynamic as well as genetic (including familial) variables. Millions of people in the US population have BAV, but based on a search of ClinicalTrials.gov, only 1 registry-based clinical trial is in progress - and that study has a targeted enrollment of $500 .{ }^{10}$ A multi-institutional registry that targets a substantially larger enrollment with intention to follow for life may be necessary to power the proposed risk-hazard models. The International BAV Consortium is working on this and other means to address the current knowledge gaps (Figure 1). ${ }^{11}$ With this leap in progress we may effectively determine optimal therapeutic algorithms for BAV in a patient-specific manner.

\section{References}

1. Andreassi MG, Della Corte A. Genetics of bicuspid aortic valve aortopathy. Curr Opin Cardiol. 2016;31:585-92.

2. Meierhofer C, Schneider EP, Lyko C, Hutter A, Martinoff S, Markl M, et al. Wall shear stress and flow patterns in the ascending aorta in patients with bicuspid aortic valves differ significantly from tricuspid aortic valves: a prospective study. Eur Heart J Cardiovasc Imaging. 2013;14:797-804.

3. Mahadevia R, Barker AJ, Schnell S, Entezari P, Kansal P, Fedak PW, et al. Bicuspid aortic cusp fusion morphology alters aortic three-dimensional outflow patterns, wall shear stress, and expression of aortopathy. Circulation. 2014;29: 673-82.

4. Atkins SK, Cao K, Rajamannan NM, Sucosky P. Bicuspid aortic valve hemodynamics induces abnormal medial remodeling in the convexity of porcine ascending aortas. Biomech Model Mechanobiol. 2014;13:1209-25.

5. Atkins SK, Sucosky P. Etiology of bicuspid aortic valve disease: focus on hemodynamics. World J Cardiol. 2014;6:1227-33.

6. Youssefi P, Gomez A, He T, Anderson L, Bunce N, Sharma R, et al. Patient-specific computational fluid dynamics - assessment of aortic hemodynamics in a spectrum of aortic valve pathologies. J Thorac Cardiovasc Surg. 2017;153:8-20.e3.

7. Bissel MM, Hess AT, Biasiolli L, Glaze SJ, Loudon M, Pitcher A, et al. Aortic dilation in bicuspid aortic valve disease: flow pattern is a major contributor and differs with valve fusion type. Circ Cardiovasc Imaging. 2013;6:499-507.

8. Regeer MV, Versteegh MIM, Klautz RJM, Schalij MJ, Bax JJ, Marsan NA, et al. Effect of aortic valve replacement on aortic root dilatation rate in patients with bicuspid and tricuspid aortic valves. Ann Thorac Surg. July 22, 2016. Epub ahead of print.

9. Kinoshita T, Naito S, Suzuki T, Asai T. Valve phenotype and risk factors of aortic dilatation after aortic valve replacement in Japanese patients with bicuspid aortic valve. Circ J. 2016;80:1356-61.

10. Bicuspid aortic valve registry (BAV). Available at: https://clinicaltrials.gov/ct2/ show/NCT01756222. Accessed Oct 28, 2016.

11. Della Corte A, Body SC, Booher A, Schaefers HJ, Milewski RK, Michelena HI et al. Surgical treatment of bicuspid aortic valve disease: knowledge gaps and research perspectives. J Thorac Cardiovasc Surg. 2014;147:1749-57. 